\title{
Childhood and adult tuberculosis in a rural hospital in Southeast Ethiopia: a ten-year retrospective study
}

\author{
Jose Manuel Ramos*1,2, Francisco Reyes and Abraham Tesfamariam
}

\begin{abstract}
Background: Many DOTS experiences in developing countries have been reported. However, experience in a rural hospital and information on the differences between children and adults are limited. We described the epidemiology and treatment outcome of adult and childhood tuberculosis (TB) cases, and identified risk factors associated with defaulting and dying during TB treatment in a rural hospital over a 10-year period (1998 to 2007).

Methods: Retrospective data collection using TB registers and treatment cards in a rural private mission hospital. Information was collected on number of cases, type of TB and treatment outcomes using standardised definitions.

Results: 2225 patients were registered, $46.3 \%$ of whom were children. A total of 646 patients had smear-positive pulmonary TB (PTB), [132 (20.4\%) children]; 816 had smear-negative PTB [556 (68.2\%) children], and 763 extra-PTB (EPTB) [341 (44.8\%) children]. The percentage of treatment defaulters was higher in paediatric (13.9\%) than in adult patients (9.3\%) $(p=0.001)$. The default rate declined from $16.8 \%$ to $3.5 \%$, and was independently positively associated with TB meningitis (AOR: $2.8 ; 95 \% \mathrm{Cl}: 1.2-6.6$ ) and negatively associated with smear-positive PTB (AOR: 0.6; 95\% Cl: 0.40.8). The mortality rate was $5.3 \%$ and the greatest mortality was associated with adult TB (AOR: $1.7 ; 95 \%$ Cl: $1.1-2.5)$, TB meningitis (AOR: 3.6; 95\% Cl:1.2-10.9), and HIV infection (AOR: 4.3; 95\% Cl: 1.9-9.4). Decreased mortality was associated with TB lymphadenitis (AOR: 0.24; 95\% Cl: 0.11-0.57).
\end{abstract}

Conclusion: (1) The registration of TB cases can be useful to understand the epidemiology of TB in local health facilities. (2) The defaulter and mortality rate of childhood TB is different to that of adult TB. (3) The rate of defaulting from treatment has declined over time.

\section{Background}

Tuberculosis (TB) is one of the leading causes of morbidity and death in adults in sub-Saharan African countries. Ethiopia is among the 22 countries with the highest TB burden in the world. Detection and treatment of new cases in Directly Observed Treatment Short course chemotherapy (DOTS) programmes is believed to be the most valuable strategy for TB control [1]. By the end of 2006, 184 countries had adopted and implemented DOTS programmes. In 1992 the National Tuberculosis and Leprosy Control Programme (TLCP) and DOTS strategy were established in Ethiopia, with guidelines that make it necessary to fill out a TB register [2,3]. A DOTS strategy

\footnotetext{
* Correspondence: jramosrincon@yahoo.es

1 Gambo General Rural Hospital, POB 121, Shashemane, Ethiopia Full list of author information is available at the end of the article
}

was introduced in the tuberculosis control programme at Gambo Rural Hospital (GRH) in 1996. In Ethiopia, the resources for accurate TB diagnosis are basic, and culture and drug susceptibility testing for Mycobacterium tuberculosis are not performed routinely.

Children account for a substantial proportion of the global burden of tuberculosis [4]. Childhood TB nevertheless remains neglected for various reasons, mainly the difficulty in diagnosing pulmonary TB, the lack of scientific studies on childhood TB, the largely unknown outcome of children with $\mathrm{TB}$, and the dogma that childhood TB is not important in TB control [4-6]. Moreover, children in TB-endemic areas suffer severe TB related morbidity and mortality, and a large proportion of cases are diagnosed solely on the basis of medical history and clinical examination $[4,6]$. In Ethiopia, childhood TB is still a 
major cause of hospital admission and death $[5,6]$. Surveillance systems to monitor TB outcome in children are very important in order to know the risk factors associated with an unfavorable outcome [6]. The most critical need is for improved capability to confirm diagnosis in the developing world. Several authors have recommended a prompt and efficient identification of source of transmission, family screening and early initiation of treatment for the prevention and control of tuberculosis in children $[5,6]$.

Many DOTS experiences in developing countries have been reported [7-11]. However, experience in a rural hospital and information on the differences between children and adults are limited. For instance, in the present study, we sought to describe the experience of tuberculosis according to the TLCP in a rural zone in Southeast Ethiopia over a period of 10 years (1998 to 2007). Furthermore, we compare childhood TB with adult TB, and identify risk factors associated with defaulting and dying during TB treatment.

\section{Methods \\ Setting}

The GRH is a 135-bed rural general hospital located in West-Arsi zone, $250 \mathrm{Km}$ south of Addis Ababa. The GRH is a private mission hospital. Due to an inadequate transportation network, the catchment area of the GRH is restricted to approximately 75,000 inhabitants. Most of the population live in a rural setting and work in agriculture and farming.

\section{Study design and data collection}

The TLCP adopted the WHO recording and reporting guidelines recommended in 1992 [2,3]. Briefly, patients with signs and symptoms suggestive of TB are screened for confirmation of the diagnosis and initiation of treatment. Patients with symptoms compatible with pulmonary tuberculosis (PTB) submit three sputum samples. Patients with at least two positive smears are considered to have smear-positive PTB; those with three negative smears are treated with antibiotics and then re-evaluated. These latter patients are considered to have smear-negative PTB if they had a chest $x$-ray suggestive of PTB and did not respond to a course of antibiotics. The diagnosis of extra-pulmonary TB (EPTB) is usually made clinically according to TLCP guidelines [2,3]; biopsies of lymphadenopathies, lumbar puncture, pleural and peritoneal effusion puncture were usually performed.

Patients who are diagnosed with TB at GRH were: 1) admitted to hospital in the case of seriously ill PTB or EPTB patients, 2) registered at the GRH TB clinic or 3) referred to TB clinics near their home. During the period of study (1998 to 2007), all of the patients were included in the DOTS programme. The patients were usually admitted to hospital for two months (intensive phase). The cost of hospitalization was 3 times lower than in adults admitted for other reasons. In addition, the children's admission fee was 4 times lower than that of adults. The food was provided by the hospital. After being discharged, the patients could continue to attend the GRH TB clinic or were transferred to TB clinics near their home. During the intensive phase the patients took their medication daily under the direct observation of a health worker. Patients who lived more than an hour's walk from the GRH TB clinic were provided with free accommodation in a house near the TB clinic for two months. During the continuation phase the drugs were given monthly, and were self-administered. There were three categories of treatment regimens: (1) short course chemotherapy for smear-positive PTB and seriously ill smear-negative PTB and EPTB cases, (2) retreatment regimen, (3) short course chemotherapy for smear negative PTB and EPTB patients who were not seriously ill. However the scheme changed during the period of study as shown in Table 1. TB treatment is free for patients.

The health workers completed the case notification forms, which include details of age, sex, weight, disease status (new case, relapse, return after default, treatment failure, transferred into the GRH), type of TB (smear-positive PTB, smear-negative PTB, EPTB), treatment regimen, treatment outcome (cured, completed treatment, defaulter, failure of treatment, died or transferred out), immunodeficiency virus (HIV) status and other clinicalepidemiological data (such as the score on the chart for diagnosis of $\mathrm{TB}$ in children, other relatives with $\mathrm{TB}$, and previous TB diagnosis). The HIV test was only performed in patients with other clinical signs suggestive of HIV infection before 2007 because the HIV test was not generally available. During 2007, the HIV test was done in almost all cases. Institutional ethical clearance was obtained from the Research and Publication Committee of the GRH and the Health Unit and Ethical Review Committee of the Ethiopian Catholic Secretariat.

\section{Statistical analysis}

The epidemiological and clinical data were entered in an Excel 97 program. Data was analysed using the SPSS, version 12, statistical package. Continuous variables are given as medians and interquartile range (IQR). Fisher's exact test, Student's $\mathrm{t}$ test and Kruskal-Wallis test were used for comparison where appropriate. Each category was analysed comparing it to the rest of the cases. Crude odds ratios (OR) and $95 \%$ confidence intervals (CI) were used for the interpretation of the univariate analysis. Significant univariate predictors $(\mathrm{p}<0.05)$ of mortality and default from treatment were included in a stepwise logistic regression model to identify independent predictors (adjusted odds ratios (AOR) and 95\% CI). 
Table 1: Scheme of treatment according to type of tuberculosis following the Tuberculosis and Leprosy Prevention and Control Programme in Ethiopia.

\begin{tabular}{llll}
\hline & 2005 Guidelines & 2002 Guidelines & \\
\hline Category I: & & 1999 Guidelines & \\
Short course chemotherapy for & Adults & Adults & Adults \\
smear-positive PTB and seriously & Children $<7$ years & $2(\mathrm{ERHZ}) / 6(\mathrm{EH})$ or 2(SRHZ)/6(EH) & 2(SRHZ)/6(TH) or 2(ERHZ)/6(TH) \\
ill smear-negative PTB and EPTB & $2(\mathrm{SRHZ}) / 4(\mathrm{RH})$ & Children $<7$ years & Children \\
cases & Children $\geq 7$ years & $2(\mathrm{SRHZ}) / 4(\mathrm{RH})$ & 2(SRHZ)/6(TH) \\
& $2(\mathrm{ERHZ}) / 4(\mathrm{RH})$ & Children $\geq 7$ years & $2(\mathrm{ERHZ}) / 6(\mathrm{EH})$
\end{tabular}

\section{Category II:}

Retreatment regimen

$\begin{array}{ll}\text { Category Illa: } & \text { Adults } \\ \text { Short course chemotherapy for } & 2(\mathrm{RHZ}) / 6(\mathrm{EH}) \\ \text { smear negative PTB, EPTB who are } & \text { Children }<7 \text { years } \\ \text { not seriously ill } & 2(\mathrm{RHZ}) / 4(\mathrm{RH}) \\ & \text { Children } \geq 7 \text { years } \\ & 2(\mathrm{RHZ}) / 6(\mathrm{EH}) \text { or } \\ & 2(\mathrm{RHZ}) / 4(\mathrm{RH})\end{array}$

\section{Category IIIb:}

Long course chemotherapy for smear negative PTB, EPTB who are not seriously ill

\section{SERHZ/1ERHZ/5 (ERH)3}

Adults

2 (RHZ)/6 (EH)

Children $<7$ years

$2(\mathrm{RHZ}) / 4(\mathrm{RH})$

Children $\geq 7$ years

$2(\mathrm{RHZ}) / 6(\mathrm{EH})$

PTB: pulmonary tuberculosis; EPTB: extrapulmonary tuberculosis; $\mathrm{H}$, isoniazid; $\mathrm{R}$, rifampicin; S: streptomycin; Z: pirazinamide; E: ethambutol; T: thioacetazon

\section{Results}

Over the 10-year period from 1998 to 2007, 2225 patients with all forms of TB were registered for treatment. The decrease in the number of registered TB cases from 381 in 1998 and 310 in 1999 to 156 in 2000 correlated with the segregation of part of a rural zone, because of decentralisation of the DOTS strategy in the region (Table 2). Two thousand one hundred and twenty eight patients (95.5\%) were newly diagnosed and 49 (2.2\%) had been treated previously for TB, with no marked differences throughout the years (Table 3). Twenty-nine percent had smear-positive PTB, 36.7\% smear-negative PTB and $34.3 \%$ EPTB, and no differences were seen throughout the study period (Table 3$)$. The type of EPTB $(n=762)$ was: TB lymphadenitis in 411 (53.9\% of all EPTB cases), osteoarticular TB in 171 (24.4\%), abdominal TB in 112 (14.7\%), and TB meningitis in 26 (3.4\%) (Table 3).

The median age was 17 years (IQR: 7 - 27) and 51.4\% were male. Of the 2225 patients registered, in two cases the age was not recorded and 1029 (46.3\%) were children (under 15 years old). The median age of childhood TB was 6 years (IQR: 1.5 - 11), and 34.1\% were under the age of 3 years. In adults the median age was 26 (IQR: 20 - 36), and $67.3 \%$ of them were under the age of 31 years. Thirtyeight patients $(1.7 \%)$ were HIV positive. The percentage of patients tested for HIV was $12.3 \%$. During the period of study the number of patients tested for HIV status increased, especially during the last year. Of all the cases,
38 patients (1.7\%) were HIV positive, and amongst the patients tested, $13.6 \%$ were positive.

\section{Differences between childhood and adult TB}

Of the 646 patients with smear-positive PTB, 132 (20.4\%) were children; of the 816 with smear-negative PTB, 556 (68.2\%) were children; and of the 763 with EPTB, 341 (44.8\%) were children. Table 3 shows the differences in the epidemiology, case definitions, forms of $\mathrm{TB}$, and treatment outcome between paediatric and adult patients. Significant differences were found as regards newly diagnosed TB cases (97.5\% vs. $94.1 \%$; $\mathrm{p}<0.001)$, and relapses $(0.7 \%$ vs. $3.4 \% ; \mathrm{p}<0.001)$ between paediatric and adult patients. Both the number of patients tested for HIV and the number found to be HIV positive were less in paediatric cases than in adults $(0.4 \%$ and $5.4 \%$ vs. $2.8 \%$ and $18.8 \%$, respectively; $\mathrm{p}<0.001)$. In childhood TB, smear-positive PTB was significantly less frequent, whereas smear-negative PTB and TB meningitis were more common. The number who defaulted from treatment was higher in paediatric $(13.9 \%)$ than in adult patients $(9.3 \%)(p=0.001)$. The mortality rate was lower in paediatric patients $(3.9 \%)$ than in adults $(6.5 \%)(\mathrm{p}=$ $0.008)$.

\section{Treatment outcome}

The treatment outcome reports were not available (unknown) in $2.8 \%$ (15.8\% in 1998, and $2.1 \%$ in 1999). The transfer out rate was $13.5 \%$, with no marked differences 
Table 2: Evolution of forms of tuberculosis (TB), case definitions, tuberculosis in children, and treatment outcome during 10-year period of study.

\begin{tabular}{|c|c|c|c|c|c|c|c|c|c|c|}
\hline & 1998 & 1999 & 2000 & 2001 & 2002 & 2003 & 2004 & 2005 & 2006 & 2007 \\
\hline All forms of TB, $n$ & 381 & 310 & 173 & 156 & 171 & 190 & 231 & 224 & 202 & 187 \\
\hline Smear-positive PTB, \% & 18.6 & 23.2 & 31.8 & 42.9 & 35.1 & 31.6 & 39.4 & 23.7 & 28.7 & 31.6 \\
\hline Smear-negative PTB, \% & 53.5 & 44.2 & 32.4 & 18.6 & 31.0 & 29.5 & 25.6 & 27.9 & 34.7 & 35.8 \\
\hline EPTB, n \% & 27.8 & 32.6 & 35.8 & 38.5 & 33.9 & 38.9 & 35.1 & 38.4 & 36.6 & 32.6 \\
\hline \multicolumn{11}{|l|}{ Case definitions } \\
\hline New cases, $\%$ & 95.7 & 96.4 & 96.5 & 95.7 & 95.6 & 96.1 & 93.5 & 96.0 & 96.8 & 94.7 \\
\hline Relapse, \% & 0.9 & 2.2 & 2.0 & 3.2 & 2.2 & 1.0 & 2.3 & 3.5 & 2.6 & 3.5 \\
\hline Transfer in, \% & 2.6 & 0.9 & 1.5 & 0 & 1.7 & 1.8 & 3.2 & 0.6 & 0.6 & 1.8 \\
\hline Other, \% & 0.9 & 0.4 & 0 & 0 & 0.4 & 1.0 & 1.0 & 0 & 0 & 0 \\
\hline Tuberculosis in children, $\%$ & 61.7 & 54.5 & 42.2 & 32.7 & 45.0 & 43.2 & 43.9 & 49.6 & 38.6 & 28.0 \\
\hline Hospital admission, $\%$ & 33.9 & 15.5 & 20.2 & 38.5 & 51.5 & 54.7 & 42.4 & 58.9 & 46.5 & 38.5 \\
\hline \multicolumn{11}{|l|}{ HIV status } \\
\hline Negative, \% & - & - & - & - & 0.6 & 8.9 & 5.6 & 10.3 & 19.3 & 79.7 \\
\hline Positive, $\%$ & 0.5 & 0.3 & 0.6 & 3.2 & 2.3 & 1.1 & 3.0 & 0.9 & 2.5 & 4.8 \\
\hline Unknown*, \% & 99.5 & 99.7 & 99.4 & 96.8 & 97.1 & 90.0 & 91.3 & 88.8 & 78.2 & 15.5 \\
\hline \multicolumn{11}{|l|}{ Treatment outcome } \\
\hline Cured, \% & 13.9 & 15.5 & 26.6 & 23.1 & 17.5 & 17.4 & 25.1 & 17.0 & 17.8 & 17.5 \\
\hline Treatment completed, \% & 46.7 & 48.7 & 59.0 & 50.6 & 45.0 & 52.1 & 50.6 & 46.9 & 52.5 & 53.0 \\
\hline Transfer out, \% & 15.2 & 17.7 & - & 5.1 & 15.2 & 17.4 & 8.2 & 17.9 & 14.9 & 21.9 \\
\hline Death, \% & 4.3 & 3.2 & 2.9 & 9.0 & 10.5 & 5.8 & 6.5 & 7.1 & 5.0 & 2.7 \\
\hline Failure, \% & - & 1.0 & 0.6 & 0.6 & - & - & - & - & - & - \\
\hline Defaulted, \% & 19.8 & 13.9 & 11.0 & 11.5 & 11.7 & 7.4 & 9.5 & 11.2 & 9.9 & 4.9 \\
\hline
\end{tabular}

* not done; HIV: human immunodeficiency virus; PTB: pulmonary TB; EPTB: extrapulmonary TB

throughout the years. The failure rate was $0.2 \%$. The average treatment success rate (cured plus treatment completed) was $66.9 \%$, with no marked differences throughout the years. In smear-positive PTB cases, the treatment success rate was $71.9 \%$ (cured: $60.9 \%$, and treatment completed: $11.0 \%)$.

\section{Defaulting from treatment}

The defaulting from treatment rate was $11.4 \%$, and decreased from $16.8 \%$ in 1998 to $4.9 \%$ in 2007 . Of the 300 patients who defaulted from treatment, $37.1 \%$ did so by the end of the intensive phase. The median number of days before defaulting was 90 (IQR: 60-120). Results of the univariante analysis are shown in Table 4. On multivariate analysis, a higher defaulting from treatment rate was independently associated with TB meningitis (AOR: 2.8; 95\% CI: 1.2-6.6), and smear-positive PTB was less frequently associated with defaulting (AOR: 0.47; 95\% CI: 0.34-0.67).

\section{Mortality}

Of the 2163 patients diagnosed with TB whose outcomes were available, 112 (5.3\%) died. The median survival time from time of diagnosis for those who died was 28.5 days (IQR: 9.75-59.5). Paediatric patients who died had significantly shorter survival than adult patients (median 10 [IQR:3-34.5] vs. 37 days [IQR:18-65], respectively, $\mathrm{P}<$ 0.001). Patients who died were significantly older than those who survived (median age 22 [IQR: 0-35] vs. 17 [IQR: 7-26] years, respectively, $\mathrm{P}<0.001)$. Results of the univariate analysis of risk factors for death among patients diagnosed with tuberculosis are shown in Table 4. On multivariate analysis, increased mortality was associated with adults (AOR: 1.7; CI95\%: 1.1-2.5), TB meningitis (AOR: 3.6; CI 95\%:1.2-10.9), and HIV infection (AOR: 4.3; CI 95\%:1.9-9.4); moreover, decreased mortality was associated with TB lymphadenitis (AOR: 0.24; CI 95\%: 0.11-0.57).

\section{Discussion}

TB is a disease with diverse clinical manifestations. According to the TLCP, PTB should account for $80 \%$ of all TB cases (smear-positive PTB comprises $75-80 \%$ and smear-negative PTB 20-25\% of all PTB cases), and EPTB $20 \%$ of all TB cases [2]. The distribution of the patients in 
this study according to the classification of tuberculosis was: $65.3 \%$ PTB (smear-positive, $44.2 \%$, and smear-negative, 55.8\%) and 34.3\% EPTB. These results were similar to the findings of an eight-year overview (1998-2007) of TB case notification in Ethiopia, according to the TLCP [3]. However, if we consider only adult TB, PTB accounts for $64.7 \%$ of all TB cases (smear-positive PTB, $66.5 \%$ and smear-negative, 33.5\%) and ЕРТВ $35.3 \%$ of all TB cases. The percentage of PTB was slightly lower than in the TLCP [2,3] recommendations and Yassin et al's study [7] (72\%) and closer to that found by Shargie EB and Lindtjørn B [8] (67.7\%).

$\mathrm{HIV}$ infection increases the susceptibility to TB [9]. In this study the prevalence of TB and HIV co-infection was $1.7 \%$. However, less than $10 \%$ of TB cases were tested for HIV. Only the data from the last year of study can truly reflect the HIV status. In the last year of the study period, the prevalence reached 5\%. Studies in sub-Saharan Africa have shown that the prevalence of TB and HIV co-infection is more than $5 \%[10,11]$, and according to the WHO report the prevalence of co-infection was $11 \%$ [1]. In our study, the patients came from rural areas and the prevalence was lower.

The reported percentage of all TB cases occurring in children varies from $3 \%$ to more than $25 \%$ depending on the country $[12,13]$. This study shows that nearly $43 \%$ of registered TB cases in GRH were children aged 14 years or under. The largest reported number of cases of childhood TB notified in sub-Saharan Africa is 39\%, from a poor and crowded urban population in South Africa [14]. This survey probably represents an over-estimate of the real burden of $\mathrm{TB}$ in Ethiopian children [3,13]. In a Malawi study [14], a mission hospital, like the GRH, in a rural district recorded significantly higher rates of $\mathrm{TB}$ than did the district hospital. Mission hospitals, some of which have paediatric services, and probably more adequate clinical and diagnostic services, are likely to detect a higher rate of childhood TB, as did the GRH. The high proportion of childhood TB compared to adult TB may be explained by the higher rate of admission of children to GRH (60\%) since it is a missionary hospital. Many adults are diagnosed outside the hospital, whereas children would go to this hospital to be diagnosed because it was cheap compared to other clinics and it was possible to do a chest-X-ray. Moreover, the high proportion of childhood TB should be a good incentive for our hospital to review diagnostic procedures in children. It is often very difficult to diagnose $\mathrm{TB}$ in children and it may be over-diagnosed even though we followed national guidelines.

The predominant types of childhood TB were smearnegative PTB followed by EPTB, with smear-positive PTB being the least common. This would be expected because of the acknowledged difficulties involved in con- firming PTB in children and young adults in samples of expectorated sputum [3,13-16]. Smear-negative PTB cases accounted for $54 \%$ of all childhood TB cases, EPTB for $33.1 \%$ and smear-positive PTB $12.8 \%$. The incidence of TB in HIV-infected African children is low compared to HIV-infected African adults [17]. In this study the HIV prevalence was low among children with TB compared to adults with $\mathrm{TB}$.

In the patients described here, the treatment success rate was about $70 \%$. This is lower than previously report by the TLCP in Ethiopia (from 78\% to 85\%) [3]. More than $40 \%$ of cases were admitted to hospital. The admitted cases are more seriously ill patients, and after the initial phase of treatment are discharged and transferred out to their TB clinic. In these patients it is impossible to know if they are cured or if they complete treatment.

In this study, the default rate $(11.3 \%)$ falls somewhere between the rate reported in the study by Yassin et al [4] in Ethiopia (6\%), and that found by Shargie EB and Lindtjørn B [18] (20\%). However, there was a significant improvement over the 10-year study period since the rate fell from $19.8 \%$ in 1998 to $4.9 \%$ in 2007 . The defaulter rate declined in other studies in Ethiopia, for example from $24 \%$ in 1996 to $6 \%$ in 2004 in Yassin et al's [7] study or from $38 \%$ to $18 \%$ in Shargie EB and Lindtjørn B's [8] study. The likely causes of this drop are the short treatment regimens used during the last years of the study and the decrease in distance between the homes and treatment centre throughout the period of study. Patients with smear-positive PTB were more likely to complete treatment, possibly because their illness is more severe and symptomatic [19-22]. The higher defaulting rate among the TB meningitis patients is probably due to their more severe illness and neurological deficits. The high prevalence of default could be partially due to cases of death at home, especially in cases that occur after the intensive phase of treatment.

This study shows that the death rate (5.3\%) was lower than in other studies conducted in sub-Saharan African countries (about 23\%) [23]. The reason for this is not clear; defaulter rates in this study were higher, and it is possible that a large number of deaths are hidden in this outcome category. TB in adults, TB meningitis and HIV infection were associated with increased risk of death.

These findings are subject to at least five limitations. First, sociological data were not available, and the information that was available, recovered from registers, may be imprecise in some cases. Second, we were unable to collect information about HIV infection, which might have affected the likelihood of a poor outcome. Testing for HIV was performed only occasionally before 1998 and usually only positive results were annotated, with no negative requests being recorded. During the last year, the test was performed in nearly all the cases following TLCP 
Table 3: Differences in epidemiological data, case definitions, forms of tuberculosis (TB), and treatment outcome between paediatric and adult patients [ $>14$ years].

\begin{tabular}{|c|c|c|c|c|}
\hline & $\begin{array}{c}\text { Total } \\
\text { (\%) }\end{array}$ & $\begin{array}{l}\text { Paediatric patients } \\
\text { (n= 1029) } \\
(\%)\end{array}$ & $\begin{array}{c}\text { Adult patients } \\
\text { (n= 1194) } \\
(\%)\end{array}$ & P value \\
\hline \multicolumn{5}{|l|}{ Epidemiological } \\
\hline Sex, female & $1145(51.5)$ & $553(53.7)$ & $592(49.6)$ & 0.05 \\
\hline Hospital admission & $860(38.7)$ & $408(38.7)$ & $452(37.9)$ & 0.5 \\
\hline \multicolumn{5}{|l|}{ HIV status } \\
\hline Negative & $242(10.9)$ & $51(5.0)$ & $191(16.0)$ & $<0.001$ \\
\hline Positive & $38(1.7)$ & $4(0.4)$ & $34(2.8)$ & $<0.001$ \\
\hline Unknown* & $1943(87.4)$ & $974(94.7)$ & $969(81.2)$ & $<0.001$ \\
\hline \multicolumn{5}{|l|}{ Case definitions } \\
\hline New cases & $2126(95.5)$ & $1003(97.5)$ & $1123(94.1)$ & $<0.001$ \\
\hline Relapses & $48(2.2)$ & $7(0.7)$ & $41(3.4)$ & $<0.001$ \\
\hline Other & $10(0.4)$ & $5(0.5)$ & $5(0.4)$ & 0.2 \\
\hline Transfer in & $37(1.7)$ & $13(1.3)$ & $24(2.0)$ & 0.4 \\
\hline \multicolumn{5}{|l|}{ Forms of TB } \\
\hline Smear-positive PTB & $646(29.0)$ & $132(12.8)$ & $514(43.0)$ & $<0.001$ \\
\hline Smear-negative PTB & $815(36.4)$ & $556(54.0)$ & $259(21.7)$ & $<0.001$ \\
\hline All forms of EPTB & $762(34.3)$ & $341(33.1)$ & $421(35.3)$ & 0.3 \\
\hline TB lymphadenitis & $411(19.5)$ & $189(19.1)$ & $222(19.8)$ & 0.4 \\
\hline TB osteomyelitis & $171(8.1)$ & $78(7.9)$ & $93(6.1)$ & 0.5 \\
\hline TB abdominal & $112(5.0)$ & $39(3.8)$ & $73(7.8)$ & 0.4 \\
\hline TB meningitis & $26(1.2)$ & $22(2.2)$ & $4(0.4)$ & $<0.001$ \\
\hline TB pleural & $19(0.9)$ & $3(0.3)$ & $16(1.4)$ & 0.01 \\
\hline Other EPTB & $23(1.1)$ & $10(1.0)$ & $13(1.2)$ & 0.6 \\
\hline \multicolumn{5}{|l|}{ Treatment outcome } \\
\hline Cured & $402(18.1)$ & $99(9.6)$ & $303(25.4)$ & $<0.001$ \\
\hline Treatment completed & $1082(48.7)$ & $584(56.8)$ & $498(41.7)$ & $<0.001$ \\
\hline Defaulted & $254(11.4)$ & $143(13.9)$ & $111(9.3)$ & 0.001 \\
\hline Death & $118(5.3)$ & $40(3.9)$ & $78(6.5)$ & 0.008 \\
\hline Failure & $5(0.2)$ & 0 & $5(0.4)$ & 0.2 \\
\hline Transfer out & $300(13.5)$ & $126(12.2)$ & $174(14.6)$ & 0.1 \\
\hline Unknown & $63(2.8)$ & $37(3.6)$ & $26(2.1)$ & 0.5 \\
\hline
\end{tabular}

* not done; HIV: human immunodeficiency virus; PTB: pulmonary TB; EPTB: extrapulmonary TB.

recommendations to apply the procedure to the majority of cases of TB. Third, the GRH is a private hospital and patients came from other health facilities to be diagnosed. Fourth, the patients were then admitted to hospital and after finishing the intensive phase transferred out to their health facilities. Thus failure and death were not detected. Fifth, the treatment regimens changed during the period of study and this may contribute to the results found.

\section{Conclusions}

Despite these limitations, several conclusions may be drawn from our results. First, the registration of TB cases can be useful to understand the epidemiology of TB in 
Table 4: Univariante analysis of risk factors for treatment default and death among diagnosed tuberculosis (TB) patients.

\begin{tabular}{|c|c|c|c|c|c|c|}
\hline & \multicolumn{3}{|c|}{ Treatment default } & \multicolumn{3}{|c|}{ Death } \\
\hline & $\begin{array}{l}\text { Default* } \\
(\mathrm{n}=254)\end{array}$ & OR $(95 \% \mathrm{Cl})$ & p-value & $\begin{array}{c}\text { Died }^{*} \\
(n=118)\end{array}$ & OR $(95 \% \mathrm{Cl})$ & p-value \\
\hline \multicolumn{7}{|l|}{ Sex } \\
\hline Female & $116(11.0)$ & 1 & & $52(5.3)$ & 1 & \\
\hline Male & $138(12.5)$ & $1.15(0.88-1.49)$ & 0.3 & $62(5.6)$ & $1.05(0.72-153)$ & 0.8 \\
\hline \multicolumn{7}{|l|}{ Age, year } \\
\hline $0-14$ & $143(14.4)$ & 1 & & $40(4.0)$ & 1 & \\
\hline$>14$ & $111(9.5)$ & $0.62(0.48-0.81)$ & $<0.001$ & $78(6.7)$ & $1.70(1.15-2.51)$ & 0.008 \\
\hline \multicolumn{7}{|l|}{ Case definitions } \\
\hline New cases & $243(11.8)$ & $1.03(0.5-1.94)$ & 0.9 & $111(5.4)$ & $0.72(0.32-1.59)$ & 0.5 \\
\hline Relapses & $3(6.3)$ & $0.49(0.16-1.51)$ & 0.3 & $3(6.3)$ & $1.15(0.35-3.78)$ & 0.6 \\
\hline \multicolumn{7}{|l|}{ Forms of TB } \\
\hline Smear-positive PTB & $45(7.0)$ & $0.47(0.34-0.67)$ & $<0.001$ & $40(6.3)$ & $1.24(0.83-1.83)$ & 0.3 \\
\hline Smear-negative PTB & $113(14.5)$ & $2.33(1.79-3.03)$ & $<0.001$ & $47(6.0)$ & $1.19(0.81-1.74)$ & 0.4 \\
\hline EPTB & $96(12.9)$ & $1.18(0.90-1.54)$ & 0.2 & $31(4.2)$ & $0.66(0.47-1.01)$ & 0.07 \\
\hline TB lymphadenitis & $48(12.1)$ & $1.04(0.74-1.45)$ & 0.9 & $6(1.5)$ & $0.22(0.09-0.52)$ & $<0.001$ \\
\hline TB osteomyelitis & $18(10.7)$ & $0.88(0.53-1.45)$ & 0.7 & $7(4.2)$ & $0.73(0.33-1.61)$ & 0.5 \\
\hline TB abdominal & $18(14.3)$ & $1.27(0.74-2.18)$ & 0.4 & $9(8.0)$ & $1.55(0.76-3.16)$ & 0.3 \\
\hline TB meningitis & $8(30.8)$ & $3.44(1.51-7.84)$ & 0.006 & $4(15.4)$ & $3.22(1.09-9.52)$ & 0.04 \\
\hline TB pleural & $4(21.1)$ & $2.02(0.69-5.84)$ & 0.3 & $3(15.8)$ & $3.18(0.95-11.5)$ & 0.06 \\
\hline \multicolumn{7}{|l|}{ HIV status } \\
\hline Negative-Unknown & $246(11.6)$ & 1 & & $109(9.2)$ & 1 & \\
\hline Positive & $8(21.1)$ & $2.03(0.94-4.14)$ & 0.07 & $9(23.7)$ & $5.74(2.64-12.2)$ & $<0.001$ \\
\hline
\end{tabular}

${ }^{*} \mathrm{n}(\%)$; Percentage out of total registered for treatment

local health facilities. Second, the percentage of treatment defaulters was higher in paediatric than in adult patients and the mortality rate was lower in paediatric patients than in adults. The diagnosis of childhood TB in hospitals with poor resources needs to be vastly improved. Finally, the defaulting from treatment rate has declined, and the determinants that contribute to defaulting should be included in control programmes.

\section{Competing interests}

The authors declare that they have no competing interests.

\section{Authors' contributions}

JMR was the primary researcher, conceived the study, designed, participated in data collection, conducted data analysis and drafted the manuscript for publication. FR conceived the study and participated in its design and coordination. AT assisted in data collection and preparation of the first draft of the manuscript. All authors read and approved the final manuscript.

\section{Acknowledgements}

We thank the TB officers at GRH for their assistance in collecting the data. We also thank the laboratory staff for their assistance in the microbiological diagnosis of TB, and the nursing staff for their care of the admitted patients. We also thank Judith Williams for technical support.

\section{Author Details}

${ }^{1}$ Gambo General Rural Hospital, POB 121, Shashemane, Ethiopia and IInfectious Diseases Unit, Hospital General Universitario de Elche, Camí L'Almazara, 11, 03203 Elche, Alicante, Spain

Received: 23 September 2009 Accepted: 27 April 2010

Published: 27 April 2010

\section{References}

1. World Health Organization: Global tuberculosis control: surveillance, planning and financing: WHO Report 2008. Geneva, Switzerland: WHO; 2008.

2. Federal Ministry of Health: Manual of Tuberculosis and Leprosy and TB/ HIV Prevention and Control. 3rd edition. Addis Ababa, Ethiopia. Ethio Tikur Printing Press; 2005.

3. Federal Ministry of Health: Manual of Tuberculosis and Leprosy and TB/ HIV Prevention and Control. 4th edition. Addis Ababa, Ethiopia. Ethio Tikur Printing Press; 2008.

4. Graham SM, Gie RP, Schaaf HS, Coulter JB, Espinal MA, Beyers N: Childhood tuberculosis: clinical research needs. Int J Tuberc Lung Dis 2004, 8:648-57.

5. Amsalu S, Hurrisa Z, Nuri S: Tuberculosis in children, Northwest Ethiopia. Ethiop Med J 2007, 45:159-63.

6. Muñoz-Sellart M, Yassin MA, Tumato M, Merid Y, Cuevas LE: Treatment outcome in children with tuberculosis in southern Ethiopia. Scand J Infect Dis 2009, 41:450-5 
7. Yassin MA, Datiko DG, Shargie EB: Ten-year experiences of the tuberculosis control programme in the southern region of Ethiopia. Int J Tuberc Lung Dis 2006, 10:1166-71.

8. Shargie EB, Lindtjørn B: DOTS improves treatment outcomes and service coverage for tuberculosis in South Ethiopia: a retrospective trend analysis. BMC Public Health 2005, 5:62.

9. Datiko DG, Yassin MA, Chekol LT, Kabeto LE, Lindtjørn B: The rate of TBHIV co-infection depends on the prevalence of HIV infection in a community. BMC Public Health 2008, 8:266.

10. El-Sony Al, Khamis AH, Enarson DA, Baraka O, Mustafa SA, Bjune G: Treatment results of DOTS in 1797 Sudanese tuberculosis patients with or without HIV co-infection. Int J Tuberc Lung Dis 2002, 6:1058-66.

11. Kassu A, Mengistu G, Ayele B, Diro E, Mekonnen F, Ketema D, Moges F, Mesfin T, Getachew A, Ergicho B, Elias D, Wondmikun Y, Aseffa A, Ota F: HIV and intestinal parasites in adult TB patients in a teaching hospital in Northwest Ethiopia. Trop Doct 2007, 37:222-4.

12. Stop TB, Partnership Childhood TB, Subgroup World Health Organization: Guidance for National Tuberculosis Programmes on the management of tuberculosis in children. Chapter 1: introduction and diagnosis of tuberculosis in children. Int J Tuberc Lung Dis 2006, 10:1091-7.

13. Nelson LJ, Wells CD: Global epidemiology of childhood tuberculosis. Int J Tuberc Lung Dis 2004, 8:636-47.

14. van Rie A, Beyers N, Gie RP, Kunneke M, Zietsman L, Donald PR: Childhood tuberculosis in an urban population in South Africa: burden and risk factor. Arch Dis Child 1999, 80:433-7.

15. Harries AD, Hargreaves NJ, Graham SM, Mwansambo C, Kazembe P, Broadhead RL, Maher D, Salaniponi FM: Childhood tuberculosis in Malawi: nationwide case-finding and treatment outcomes. Int J Tuberc Lung Dis 2002, 6:424-31.

16. Weismuller MM, Graham SM, Claessens NJ, Meijnen S, Salaniponi FM, Harries AD: Diagnosis of childhood tuberculosis in Malawi: an audit of hospital practice. Int J Tuberc Lung Dis 2000, 6:432-8.

17. Graham SM, Coulter JB, Gilks CF: Pulmonary disease in HIV-infected African children. Int J Tuberc Lung Dis 2001, 5:12-23.

18. Shargie $E B$, Lindtjørn B: Determinants of treatment adherence among smear-positive pulmonary tuberculosis patients in Southern Ethiopia. PLoS Med 2007, 4:e37.

19. Tekle B, Mariam DH, Ali A: Defaulting from DOTS and its determinants in three districts of Arsi Zone in Ethiopia. Int J Tuberc Lung Dis 2002. 6:573-9.

20. Santha T, Garg R, Frieden TR, Chandrasekaran V, Subramani R, Gopi PG Selvakumar N, Ganapathy S, Charles N, Rajamma J, Narayanan PR: Risk factors associated with default, failure and death among tuberculosis patients treated in a DOTS programme in Tiruvallur District, South India, 2000. Int J Tuberc Lung Dis 2002, 6:780-8.

21. Michael KW, Belachew T, Jira C: Tuberculosis defaulters from the "dots" regimen in Jimma zone, southwest Ethiopia. Ethiop Med J 2004, 42:247-53.

22. Getahun H, Maher D: Contribution of 'TB clubs' to tuberculosis control in a rural district in Ethiopia. Int J Tuberc Lung Dis 2000, 4:174-8.

23. Harries AD, Hargreaves NJ, Gausi F, Kwanjana JH, Salaniponi FM: High early death rate in tuberculosis patients in Malawi. Int J Tuberc Lung Dis 2001, 5:1000-5.

\section{Pre-publication history}

The pre-publication history for this paper can be accessed here: http://www.biomedcentral.com/1471-2458/10/215/prepub

doi: $10.1186 / 1471-2458-10-215$

Cite this article as: Ramos et al., Childhood and adult tuberculosis in a rural hospital in Southeast Ethiopia: a ten-year retrospective study BMC Public Health 2010, 10.215

\section{Submit your next manuscript to BioMed Central} and take full advantage of:

- Convenient online submission

- Thorough peer review

- No space constraints or color figure charges

- Immediate publication on acceptance

- Inclusion in PubMed, CAS, Scopus and Google Scholar

- Research which is freely available for redistribution

Submit your manuscript at www.biomedcentral.com/submit
C Biomed Central 